\title{
Prevalence of Helicobacter pylori at oral and gastrointestinal sites in children: evidence for possible oral-to-oral transmission
}

\author{
R. P. ALLAKER, K. A. YOUNG, J. M. HARDIE, P. DOMIZIO* and N. J. MEADOWS $\dagger$ \\ Oral Microbiology, Department of Clinical and Diagnostic Oral Sciences, * Department of Histopathology and \\ $\dagger$ Department of Paediatric Gastroenterology, Barts and The London, Queen Mary's School of Medicine and \\ Dentistry, London E1 2AD, UK
}

\begin{abstract}
Acquisition of Helicobacter pylori occurs mainly in childhood. However, the mode of transmission remains unclear. To help elucidate this, 100 children attending for upper gastrointestinal endoscopy were investigated for the presence of $\boldsymbol{H}$. pylori at various sites. $H$. pylori was detected in antral gastric biopsies by the rapid urease test (13 patients), culture (13 patients), histology (15 patients) and PCR (20 patients). Gastric juice was positive for $H$. pylori in 3 patients by culture and 11 patients by PCR. The dental plaque from $68 \%$ of gastric biopsy-positive patients (as determined by culture or PCR) and $24 \%$ of gastric biopsy-negative patients was positive for $\mathrm{H}$. pylori by PCR. The presence of $\boldsymbol{H}$. pylori in dental plaque was significantly associated with the presence of this organism in the stomach. H. pylori was detected by PCR in the faeces of $25 \%$ of gastric biopsy-positive children sampled. $H$. pylori was not cultured on any occasion from the oral cavity or faeces. The evidence from this study suggests that oral-to-oral transmission may be a possible mode of spread of $\mathrm{H}$. pylori in children.
\end{abstract}

\section{Introduction}

Most Helicobacter pylori infections are acquired early in life, both in developed and developing countries. However, the natural history of $H$. pylori infection is poorly understood, with spontaneous eradication and subsequent re-infection probably occurring in childhood. The potential for spread of the organism via a person-to-person route may, therefore, be greater in children than in adults [1-3].

In children, H. pylori is the major cause of antral gastritis and duodenal ulcer disease [4]. Although chronic abdominal pain is the main presentation, there is no significant difference between infected and noninfected children investigated because of this or any other symptom [5]. Further studies of H. pylori infection in children may lead to a better understanding of the disease process. As regards prevalence of $H$. pylori, $10-20 \%$ of children may be infected in the UK, whereas in developing countries this may be up to $80 \%$ $[6,7]$. Little information is available within specific

Received 26 July 2001; revised version received 26 October 2001; accepted 28 October 2001.

Corresponding author: Dr R. P. Allaker (e-mail: R.P.Allaker @mds.qmw.ac.uk). paediatric populations compared with adults, and the prevalence of $H$. pylori at both gastric and non-gastric sites within children does not appear to have been studied.

The infectious dose of $H$. pylori and reservoirs of the organism must be considered to determine the relative importance of the three proposed routes of transmission: oral-oral, gastro-oral and faecal-oral. It is possible that all three may play a part in some populations. The oral cavity has been proposed as a reservoir of $H$. pylori infection and a source of reinfection following successful eradication from the stomach. The organism can certainly be detected in the mouth, but there is conflicting evidence to support the theory that it can colonise a specific niche within the oral cavity [8]. The apparent low prevalence of $H$. pylori in the mouth may be due to both a transient presence and an uneven distribution of the organism.

It has been suggested that gastric juice may play an important role in the natural route of transmission [9] as gastritis, especially the acute stage, is often accompanied by increased episodes of intermittent reflux [10] which may facilitate the passage of viable organisms into the mouth, from where they may be transmitted to other individuals. H. pylori DNA can be 
detected in the gastric juice of gastric biopsy-positive individuals by PCR [11-13] but the reported detection of viable organisms in this fluid varies greatly [14-16]. As most H. pylori infection is acquired in childhood, gastro-oral spread may be more significant in children, in whom exposure to gastric contents through vomit is more common, but information on this age group is lacking. Limited findings from fingerprint analysis of H. pylori DNA from the mouth and stomach of individual patients have demonstrated that the same strain can occur at both sites [17-19].

The aim of the present study was to determine the prevalence of $H$. pylori in the stomach, gastric juice, oral cavity and faeces of paediatric patients attending the paediatric gastro-enterology clinic of a London children's hospital. Immunomagnetic separation was used to increase the sensitivity and specificity of culture and PCR.

\section{Materials and methods}

\section{Study subjects and sample collection}

A total of 100 patients ( 45 male, 55 female; age 5 months to 16 years; mean age 8 years; 47 Caucasian, 22 Bengali, 15 Afro-Caribbean, 7 Turkish, 9 mixed origin) attending Queen Elizabeth Hospital for Sick Children for investigation by upper gastrointestinal tract endoscopy for various gastric problems was studied. Patients who had previously received anti- $H$. pylori therapy or were taking acid-suppressing medication were excluded from the study. Before endoscopy, an oral swab, rotated around the inside of the oral cavity, and a rectal swab were collected. Pooled supragingival dental plaque was obtained with two sterile toothpicks passed around the tooth margins in two quadrants of the mouth. Each sample was placed in $1 \mathrm{ml}$ of Brain Heart Infusion (BHI) Broth (Oxoid CM225). At the beginning of the endoscopy procedure, gastric juice $(0.5-10 \mathrm{ml}$, median $1 \mathrm{ml}$, mean $1.83 \mathrm{ml})$ was aspirated from the fundic pool of each patient through the endoscope and collected via a sputum trap. The $\mathrm{pH}$ of the gastric juice was measured with $\mathrm{pH}$ test strips (Sigma) and immediately neutralised with $0.67 \mathrm{M}$ Tris buffer $(\mathrm{pH} 7.4)$ if necessary. One antral gastric biopsy was taken for the rapid urease test (RUT; CLO/ 'Campylobacter-like organism' test, Delta West Ply, Bentley, Australia). In this test the biopsy is placed within the small disk of agar in the test strip to detect the presence of the H. pylori urease enzyme, indicated by a yellow to pink colour change. Histological examination of two formalin-fixed antral gastric biopsies stained with standard haematoxylin and eosin (H\&E) was performed. Two additional antral gastric biopsies were taken and placed in $1 \mathrm{ml}$ of glucose $20 \%$ $\mathrm{w} / \mathrm{v}$ for culture and DNA extraction.

\section{Sample processing}

Gastric biopsies were homogenised in a sterile tissue grinder. Oral, rectal and dental plaque samples were vortex mixed for $30 \mathrm{~s}$ before processing. Gastric juice samples were centrifuged at $13000 \mathrm{rpm}$ in a microcentrifuge for $5 \mathrm{~min}$ at room temperature and the deposit was concentrated to a volume of $1 \mathrm{ml}$. All samples were concentrated by immunomagnetic separation (IMS) with polyclonal anti-H. pylori IgG before culture and PCR [8].

\section{Bacterial culture}

A $100-\mu 1$ volume of each sample was cultured in duplicate on non-selective BHI agar (Oxoid CM375) containing defibrinated horse blood 5\%, and BHI agar containing $H$. pylori selective supplement (Oxoid SR147). Plates were incubated micro-aerobically (Campylobacter gas generating kit, Oxoid BR60) at $37^{\circ} \mathrm{C}$ for 5 days. Suspected colonies of H. pylori were identified by Gram's stain and positive reactions for catalase, oxidase and urease [20].

\section{PCR amplification}

Chromosomal DNA was extracted from all samples by the cetyltrimethyl-ammonium bromide (CTAB) method according to the DNA miniprep protocol of Wilson [21]. The primers HPU1 and HPU2 [22] were then used to amplify a 411-bp internal fragment of the urease A gene of $H$. pylori. This assay has been assessed previously for its specificity for the urease A gene of H. pylori and found not to cross-react with other Helicobacter species or known oral ureaseproducing organisms [23]. The reaction mixture (100 $\mu \mathrm{l})$ contained $0.4 \mu \mathrm{M}$ of each primer, $0.05 \mathrm{~mm}$ of each deoxynucleotide (Pharmacia), $5 \mu \mathrm{l}$ of target DNA and $2 \mathrm{U}$ of Thermus aquaticus (Taq) DNA polymerase (Pharmacia) in $10 \times$ reaction buffer. The amplification consisted of an initial denaturation of target DNA at $95^{\circ} \mathrm{C}$ for $5 \mathrm{~min}$, followed by 30 cycles of denaturation at $94^{\circ} \mathrm{C}$ for $30 \mathrm{~s}$, primer annealing at $45^{\circ} \mathrm{C}$ for $1 \mathrm{~min}$ and extension at $72^{\circ} \mathrm{C}$ for $2.5 \mathrm{~min}$. The final cycle included a further $5 \mathrm{~min}$ at $72^{\circ} \mathrm{C}$ to ensure full extension of the product. PCR reaction mixtures were electrophoresed through agarose $1 \%$ gels. H. pylori NCTC 11637 which had been incubated in Tris buffer $(0.67 \mathrm{M})$ at room temperature for $2 \mathrm{~h}$ was also subjected to DNA extraction followed by PCR to determine the minimum number of bacteria detectable by this method. H. pylori was detected by PCR at all dilutions tested to a level of $10 \mathrm{cfu} / \mathrm{ml}$. The cytotoxinassociated gene, cagA, of $H$. pylori was also detected with primers specific for this gene. The $\operatorname{cag} A$ gene, carried by c. $60 \%$ of strains expressing the cagA protein, is considered to be a marker of virulence as it is correlated with the production of the vacuolating cytotoxin, VacA [24]. 


\section{Results}

Analysis of gastric biopsy samples

H. pylori was detected in antral gastric biopsies by CLO, culture, PCR and histology in 13\%, 13\%, 20\% and $15 \%$ of patients, respectively (Table 1 ). Overall, H. pylori was detected in the stomachs of $22 \%$ of children. These were all positive by either PCR or culture, or both. The cagA gene was found in 7 (35\%) of those 20 patients who were gastric biopsy PCRpositive by the urease A method.

Histological analysis of the biopsy material revealed that 42 patients had varying degrees of chronic inflammation, 17 patients had mild or moderate inflammation, 11 had mild atrophy and one patient with $H$. pylori showed mild intestinal metaplasia. Biopsies from the remaining 58 patients were histologically normal.

\section{Symptoms}

A total of 43 children presented with recurrent abdominal pain and 17 had pain accompanied by regular vomiting (Table 2). Reflux was the major symptom in 10 patients and 6 were being investigated for coeliac disease, 8 for food allergies and 5 for suspected eating disorders. A further 11 patients who had previously been treated for $H$. pylori infections had experienced a recurrence of their original symptoms, mainly recurrent abdominal pain. All but 2 of these 11 patients were originally diagnosed and treated elsewhere for their $H$. pylori infection. All 11 children were asymptomatic and $H$. pylori-negative when checked 6-8 weeks after the initial treatment. Half of the H. pylori-positive children presented with recurrent abdominal pain, and of those children presenting with this symptom, $11(26 \%)$ of 43 were H. pylori positive. Presentation with recurrent abdominal pain as the main symptom was not significantly associated with the presence of $H$. pylori in the stomach $\left(\chi^{2}\right.$ analysis; $\mathrm{p}<0.2)$.

\section{Macroscopic findings}

The findings of macroscopic examination of the oesophagus, stomach and duodenum during endoscopy and their relationship with $H$. pylori infection are shown in Table 3. There were no abnormalities in any of the areas examined in 57 patients. In nine patients mild inflammation of the gastric antrum was seen. Ten patients showed nodularity in the antrum, but no visible inflammation. Another patient had erosions over the entire antrum. Of 13 patients with oesophagitis, two showed severe ulceration and a further two had severe reflux. One patient had an abnormally shaped stomach which prevented correct stomach emptying. Duodenal inflammation was seen in three patients, duodenal ulceration in another three patients and ulceration of the duodenal bulb in a further three patients. None of the patients had a gastric ulcer. Most of the $22 \mathrm{H}$. pylori gastric antrum-positive patients had a normal (6; $27 \%)$, slightly inflamed $(5 ; 23 \%)$ or nodular $(6 ; 27 \%)$ gastric antrum on endoscopic examination. There was a significant association between the presence of $H$. pylori in the stomach and abnormal endoscopy findings $\left(\chi^{2}\right.$ analysis; $\left.\mathrm{p}<0.01\right)$

\section{cagA gene status}

The $\operatorname{cag} A$ gene was detected in $7(35 \%)$ of 20 gastric biopsy PCR-positive patients. Table 2 shows that three of those patients who were previously $H$. pyloripositive were cagA-positive (their previous cagA status was not known). The symptoms of the other $\operatorname{cag} A$ positive patients were recurrent abdominal pain (2), reflux (1) and suspected food allergy (1). Both duodenal ulcer $H$. pylori-positive patients were $\operatorname{cag} A$ positive. Two patients with mild antral inflammation were $\operatorname{cag} A$-positive, as were two with a very nodular antrum and one whose gastric antrum was macroscopically normal. The $\operatorname{cag} A$ gene was detected in the gastric biopsy of only one patient who was cagAnegative at other PCR-positive sites.

\section{Oral samples}

H. pylori was not cultured from the dental plaque of any child. Urease A PCR of the dental plaque demonstrated that 36 children were H. pylori-positive. H. pylori was detected by this method in the dental plaque of $15(68 \%)$ of 22 gastric biopsy-positive patients and $21(24 \%)$ of 88 gastric biopsy-negative patients. The presence of $H$. pylori in dental plaque

Table 1. Detection of $H$. pylori in samples obtained from 100 pre-treatment paediatric patients

\begin{tabular}{|c|c|c|c|c|c|c|}
\hline \multirow[b]{2}{*}{ Sample } & \multirow[b]{2}{*}{$\mathrm{n}$} & \multicolumn{5}{|c|}{ Percentage of samples positive by } \\
\hline & & RUT & Histology & Culture & $\begin{array}{l}\text { Urease } \\
\text { A PCR }\end{array}$ & $\operatorname{cag} A^{*}$ \\
\hline Gastric antral biopsy & 100 & 13 & 15 & 13 & 20 & 35 \\
\hline Gastric juice & 100 & NA & NA & 3 & 11 & 36 \\
\hline Dental plaque & 100 & NA & NA & 0 & 36 & 17 \\
\hline Oral swabs & 100 & NA & NA & 0 & 23 & 17 \\
\hline Faeces & 52 & NA & NA & 0 & 8 & 0 \\
\hline
\end{tabular}


Table 2. Presenting symptoms, H. pylori infection of the stomach and the presence of the cagA gene in 100 paediatric patients

\begin{tabular}{lccc}
\hline Symptoms & $\mathrm{n}$ & $\begin{array}{c}\text { H. pylori- } \\
\text { positive }\end{array}$ & cagA-positive \\
\hline RAP & 43 & 11 & 2 \\
RAP prev HP & 11 & 3 & 3 \\
RAP and vomiting & 17 & 2 & 0 \\
Reflux & 10 & 4 & 1 \\
Possible coeliac disease & 6 & 1 & 0 \\
Food allergy & 8 & 1 & 1 \\
Eating disorder & 5 & 0 & 0 \\
Total & 100 & 22 & 7 \\
\hline
\end{tabular}

RAP, recurrent abdominal pain; RAP prev HP, patients with recurrent abdominal pain who previously were $H$. pylori-positive.

was significantly associated with the presence of the organism in the stomach $\left(\chi^{2}\right.$ analysis; $\left.\mathrm{p}<0.001\right)$. The $\operatorname{cag} A$ gene was detected in $6(17 \%)$ of 36 dental plaque PCR-positive samples, and in only one of these patients was the gastric biopsy $\operatorname{cag} A$-negative.

As with the dental plaque samples, H. pylori was never cultured from oral swabs. Urease A PCR of these samples found that 23 patients were H. pylori-positive. The cagA gene was detected in four $(17 \%)$ of these PCR-positive samples. Of the 23 patients who had a positive oral swab, 22 were also positive in dental plaque, and six had a positive gastric biopsy. There was no significant association between the presence of $H$. pylori in oral swabs and the stomach $\left(\chi^{2}\right.$ analysis; $\mathrm{p}<0.5)$.

\section{Faecal samples}

Faecal samples were collected from only 52 children; none was culture-positive and $4(8 \%)$ were urease A PCR-positive. The $\operatorname{cag} A$ gene was not detected in any of these four samples. Only 12 of these patients were gastric biopsy-positive, and one of the PCR-positive faecal samples was from a gastric biopsy-negative patient who had a positive dental plaque and oral swab. Therefore, three of the gastric biopsy-positive patients

Table 3. Endoscopy findings, $H$. pylori infection of the stomach and the presence of the cagA gene in 100 paediatric patients

\begin{tabular}{|c|c|c|c|}
\hline Endoscopy findings & $\mathrm{n}$ & $\begin{array}{l}\text { H. pylori- } \\
\text { positive }\end{array}$ & $\operatorname{cag} A$-positive \\
\hline Normal & 57 & 6 & 1 \\
\hline Mild antral inflammation & 9 & 5 & 2 \\
\hline Nodular antrum & 10 & 6 & 2 \\
\hline Antral erosions & 1 & 0 & 0 \\
\hline Oesophagitis & 13 & 1 & 0 \\
\hline Duodenal ulcer & 3 & 2 & 2 \\
\hline Duodenal bulb ulcer & 3 & 1 & 0 \\
\hline Duodenal inflammation & 3 & 1 & 0 \\
\hline Abnormal stomach shape & 1 & 0 & 0 \\
\hline Total & 100 & 22 & 7 \\
\hline
\end{tabular}

from whom faecal samples were collected were $H$. pylori-positive at this site.

\section{Gastric juice}

Gastric juice samples were collected from all 100 children. These ranged in volume from 0.5 to $10 \mathrm{ml}$ (median $1 \mathrm{ml}$ ). H. pylori was detected in the gastric juice of 3 patients by culture and 11 patients by PCR, all of whom were gastric biopsy $H$. pylori-positive. The cagA gene was detected in $4(36 \%)$ of the 11 PCR-positive gastric juice samples, all four of which were from gastric biopsy $\operatorname{cag} A$-positive patients.

The quantity of $H$. pylori cultured ranged from 4700 to $9200 \mathrm{cfu} / \mathrm{ml}$ gastric juice (mean $6533 \mathrm{cfu} / \mathrm{ml}$ ). Analysis of the gastric juice samples collected from the 22 gastric biopsy-positive patients showed that 15 of these had a $\mathrm{pH}$ of 7 , were clear in appearance and had a volume of $0.5-1 \mathrm{ml}$.

\section{Overall analysis}

Ten patients were H. pylori-positive at one site only (one gastric biopsy, eight dental plaque samples and one oral swab). Mixed infections were indicated in only two patients who carried both $\operatorname{cag} A$-positive and $\operatorname{cag} A$ negative strains at different sites. Of the gastric biopsypositive children, $32 \%$ were Bengali who were found to be 3.92 times more likely to be positive at this site than Caucasians (logistic regression odds ratio). AfroCaribbean and Turkish children were 4.2 (5 of 15 positive) and 11.2 (4 of 7 positive) times more likely to be gastric biopsy-positive than Caucasians (5 of 47 positive), respectively. Positive dental plaque samples were predominantly found with Caucasian and Bengali children (36\% and $31 \%$, respectively), whereas almost half (48\%) of all positive oral swabs were from Caucasians. Bengalis were 5 and 2.6 times more likely to be gastric juice- and dental plaque-positive than Caucasians, respectively. Afro-Caribbeans were 5.6 and 3.9 times more likely to be gastric juice- and dental plaque-positive than Caucasians, respectively.

Twice as many male than female children were gastric biopsy-positive (68\% compared with 34\%). Positive gastric juice, dental plaque and oral swabs were almost evenly split between males and females. Males were 3.6 (gastric biopsy), 1.6 (gastric juice), 1.7 (dental plaque) and 1.5 (oral swab) times more likely to be $H$. pylori-positive than females. The most prevalent age group, $6-8$ years, had the largest proportion of gastric biopsy-positive patients $(36 \%)$. The highest proportion of dental plaque-positive children (28\%) fell within the 9-11 years age group, who were twice as likely to be positive at this site than $0-2$ year olds, and 1.4 times more likely to be oral swab positive than $0-2$ year olds. 


\section{Discussion}

H. pylori was detected in the stomachs of $22 \%$ of children in this study group, of whom $35 \%$ were cagApositive. No other published studies appear to have examined the prevalence of $H$. pylori at gastric and non-gastric sites in children by culture and PCR, as well as RUT and histology. Most paediatric studies have analysed $H$. pylori status by non-invasive techniques, and so the results of this study are not directly comparable to those of others. However, the results of the present study do show similar prevalence levels to other studies conducted in developed countries. Perri et al. [25] found that 28\% of Belgian children (age range $4.5-18.5$ years) were ${ }^{13} \mathrm{C}$-urea breath test-positive. In the USA, $25 \%$ of children from a range of ethnic backgrounds (age range 6-19 years) were H. pylori seropositive [26]. However, Elitsur et al. [27] found that $40 \%$ of rural and urban children (age range 1-20 years) from Western Virginia were $H$. pylori seropositive. In Japan, seropositivity was found in $41 \%$ of those under 1 year old, $9 \%$ of those aged $1-2$ years and $35 \%$ of children aged $15-19$ years [28]. A study of London schoolchildren, aged 4-13 years, found that $17 \%$ were $H$. pylori seropositive [7]. Few studies have evaluated the $\operatorname{cag} A$ status of $H$. pyloriinfected children, but the results of this study compare well with the findings of Husson et al. [29], in whose study group $40 \%$ of children were $\operatorname{cag} A$-positive.

Male children were 3.6 times more likely to be gastric biopsy-positive than females. The reason for this is not clear. Generally, others have found no gender difference in H. pylori seroprevalence, except in certain ethnic groups in which males showed a higher seroprevalence $[30,31]$. Bengali, Afro-Caribbean and Turkish children were all more likely to be $H$. pylori gastric biopsypositive than Caucasian children. The socio-economic status of these children may have been a significant factor, but was not assessed in this study.

The prevalence of H. pylori, as determined by PCR, at the other sites tested was $11 \%, 36 \%, 23 \%$ and $8 \%$ in gastric juice, dental plaque, oral swabs and rectal swabs, respectively. H. pylori was not cultured from any of the oral cavity or faecal samples examined here, despite the use of immunomagnetic separation, which had a minimum detection level of 10 organisms by both culture and PCR. In a study of 19 asymptomatic Bangladeshi schoolchildren, Banatvala et al. [23] found that the dental plaque of $58 \%$ of subjects was positive for $H$. pylori by PCR. This figure may be higher than found in the present study because of a small sample size and choice of only Bangladeshi subjects. Although a much larger number of dental plaque-positive children were gastric biopsy-negative compared with adults $(58 \%$ versus $22 \%)$, there was a significant association between the presence of $H$. pylori in dental plaque and the stomach. The presence of $H$. pylori in oral swabs from the children was not significantly associated with the presence of the organism in the stomach. This may be due to the sites and number of samples taken.

The prevalence of $H$. pylori found in the rectal swabs of the children $(8 \%)$ is lower than that found by Thomas et al. [32] who cultured $H$. pylori from the faeces of 39\% of children aged 3-27 months. Although a visible amount of faecal material was collected on every rectal swab, analysis of a specific larger stool sample may have resulted in a higher level of detection of $H$. pylori. However, of those $H$ pylori gastric biopsy-positive patients sampled, $25 \%$ were rectal swab-positive.

H. pylori was detected in the gastric juice of only 11 children by PCR and 3 children by culture. This low level of detection was largely due to the difficulty in collecting a gastric juice sample. Only 5 of the samples collected from the 22 gastric biopsy-positive children were true gastric juice samples and contained no bile. However, the quantity of $H$. pylori cultured from the gastric juice of children (mean $6533 \mathrm{cfu} / \mathrm{ml}$ ) was almost $10^{3}$-fold higher than in adults (median 18 $\mathrm{cfu} / \mathrm{ml})$ [16]. This may indicate that when $H$. pylori is present, children have a greater load of viable organisms in their stomach available for transmission via the mouth than adults.

In the present study, most children presented with recurrent abdominal pain, with $50 \%$ of $\mathrm{H}$. pyloripositive children complaining of this symptom. Many studies have analysed the link between abdominal symptoms and carriage of $H$. pylori and found, as this study did, no clear association. A study of 945 preschool children in Germany found that the $13.4 \%$ of infected children had even fewer gastrointestinal symptoms compared with uninfected children [5]. Blecker et al. [33] concluded that no specific symptoms were associated with $H$. pylori infection in 36 children compared with $107 \mathrm{H}$. pylori-negative children. The majority of patients in the present study were histologically and endoscopically normal $(58 \%$ and $57 \%$, respectively). Severe gastritis and gastric ulcers were not found in any of the children, but three had duodenal ulcers and a further three had ulcers on the duodenal bulb. It is known that active gastritis and ulcers are rare in children [34]. Nodularity of the antrum was seen in $10 \%$ of children. This state, not seen in adults, is thought to represent a local immunological response in the gastric mucosa. Of those $H$. pylori-positive children, most were found to have a normal gastric mucosa, mild antral inflammation or a nodular antrum $(27 \%, 23 \%$ and $27 \%$, respectively). Gottrand et al. [35] also found that $27 \%$ of infected children had a normal gastric mucosa. However, in the present study abnormal endoscopy findings were significantly associated with the presence of $H$. pylori in the stomach. Gastrointestinal symptoms of the parents of the children in the present study were not 
assessed. Brenner et al. [36] found a significant association between maternal history of ulceration and $H$. pylori infection in children.

In conclusion, the present study of 100 paediatric patients has shown that $22 \%$ of those examined were H. pylori gastric biopsy-positive, and that the organism was present in the mouths and faeces of both gastric biopsy-positive and gastric biopsy-negative patients. $H$. pylori was not cultured from the oral cavity or faecal samples, indicating that a viable reservoir of the organism outside the stomach is unlikely. However, the PCR results do show that the organism was present in the mouth and faeces of $68 \%$ and $25 \%$ of those gastric biopsy-positive children sampled, respectively. The evidence from this study indicates that oral-oral transmission may be the predominant mode of spread of $H$. pylori in children. Although only a relatively small number of faecal samples was analysed, the results suggest that in this population of children, faecal-oral transmission may play a lesser role in spread of the organism.

\section{References}

1. Banatvala N, Mayo K, Megraud F, Jennings R, Deeks JJ, Feldman RA. The cohort effect and Helicobacter pylori. $J$ Infect Dis 1993; 168: 219-221.

2. Bardhan PK. Epidemiological features of Helicobacter pylori in developing countries. Clin Infect Dis 1997; 25: 973-978.

3. Xia HH, Talley NJ. Natural acquisition and spontaneous elimination of Helicobacter pylori infection: clinical implications. Am J Gastroenterol 1997; 92: 1780-1787.

4. Ashorn M. What are the specific features of Helicobacter pylori gastritis in children? Ann Med 1995; 27: 617-620.

5. Bode G, Rothenbacher D, Brenner H, Adler G. Helicobacter pylori and abdominal symptoms: a population-based study among preschool children in Southern Germany. Paediatrics 1998; 101: 634-637.

6. Lindkvist P, Asrat D, Nilsson I et al. Age at acquisition of Helicobacter pylori infection: comparison of a high and a low prevalence country. Scand J Infect Dis 1996; 28: 181-184.

7. O’Donohue JM, Sullivan PB, Scott R, Rogers T, Brueton MJ, Barltrop D. Recurrent abdominal pain and Helicobacter pylori in a community-based sample of London children. Acta Paediatr 1996; 85: 961-964.

8. Young KA, Allaker RP, Hardie JM. Morphological analysis of Helicobacter pylori from gastric biopsies and dental plaque by scanning electron microscopy. Oral Microbiol Immunol 2001; 16: $178-181$.

9. Axon ATR. Review article: is Helicobacter pylori transmitted by the gastrooral route? Aliment Pharmacol Ther 1995; 9: $585-588$.

10. Axon ATR. Acute infection with H. pylori. In: Hunt RH, Tytgat GNJ (eds) Helicobacter pylori. Basic mechanisms to clinical cure 1996. Dordrecht, Kluwer. 1996: 407-412.

11. Shimada T, Ogura K, Ota S et al. Identification of Helicobacter pylori in gastric specimens, gastric juice, saliva, and faeces of Japanese patients. Lancet 1994; 343: 1636-1637.

12. Westblom TU, Phadnis S, Yang P, Czinn SJ. Diagnosis of Helicobacter pylori infection by means of a polymerase chain reaction assay for gastric juice aspirates. Clin Infect Dis 1993; 16: $367-371$.

13. Yoshida H, Hirota K, Shiratori Y et al. Use of gastric juicebased PCR assay to detect Helicobacter pylori infection in culture-negative patients. J Clin Microbiol 1998; 36: 317-320.

14. Andersen LP, Elsborg L, Justesen T. Campylobacter pylori in peptic ulcer disease. II. Endoscopic findings and cultivation of
C. pylori. Scand J Gastroenterol 1988; 23: 760-764.

15. Varoli O, Landini MF, Laplace $\mathrm{M}$ et al. Presence of Helicobacter pylori in gastric juice. Am J Gastroenterol 1991; 86: 249.

16. Young KA, Akyon Y, Rampton DS et al. Quantitive culture of Helicobacter pylori from gastric juice: the potential for transmission. J Med Microbiol 2000; 49: 343-347.

17. Cellini L, Allocati N, Piattelli A, Petrelli I, Fanci P, Dainelli B Microbiological evidence of Helicobacter pylori from dental plaque in dyspeptic patients. New Microbiol 1995; 18: 187-192.

18. Oshowo A, Tunio M, Gillam D et al. Oral colonization is unlikely to play an important role in Helicobacter pylori infection. Br J Surg 1998; 85: 850-852.

19. Shames B, Krajden S, Fuksa M, Babida C, Penner JL. Evidence for the occurrence of the same strain of Campylobacter pylori in the stomach and dental plaque. J Clin Microbiol 1989; 27: $2849-2850$

20. Goodwin CS, Armstrong JA, Chilvers $\mathrm{T}$ et al. Transfer of Campylobacter pylori and Campylobacter mustelae to Helicobacter gen. nov. as Helicobacter pylori comb. nov. and Helicobacter mustelae comb. nov., respectively. Int $J$ Syst Bacteriol 1989; 39: 397-405.

21. Wilson K. Preparation of genomic DNA from bacteria. In Ausubel FM (ed) Current protocols in molecular biology. New York, Wiley. 1987.

22. Clayton CL, Kleanthous H, Coates PJ, Morgan DD, Tabaqchali S. Sensitive detection of Helicobacter pylori by using polymerase chain reaction. J Clin Microbiol 1992; 30: 192-200.

23. Banatvala N, Romero Lopez C, Owen RI et al. Use of the polymerase chain reaction to detect Helicobacter pylori in the dental plaque of healthy and symptomatic individuals. Microb Ecol Health Dis 1994; 7: 1-8.

24. Tummuru MRK, Cover TL, Blaser MJ. Cloning and expression of a high-molecular-mass major antigen of Helicobacter pylori: evidence of linkage to cytotoxin production. Infect Immun 1993; 61: $1799-1809$

25. Perri F, Pastore M, Clemente R et al. Helicobacter pylori infection may undergo spontaneous eradication in children: a 2-year follow-up study. J Pediatr Gastroenterol Nutr 1998; 27: $181-183$.

26. Staat MA, Kruszon-Moran D, McQuillan GM, Kaslow RA A population-based serologic survey of Helicobacter pylori infection in children and adolescents in the United States. $J$ Infect Dis 1996; 174: 1120-1123.

27. Elitsur Y, Short JP, Neace C. Prevalence of Helicobacter pylori infection in children from urban and rural West Virginia. Dig Dis Sci 1998; 43: 773-778.

28. Matsukura N, Onda M, Tokunaga A et al. Detection of serum IgG antibody against Helicobacter pylori from childhood in a Japanese population. J Gastroenterol 1994; 29: 403-405.

29. Husson M-O, Gottrand F, Vachee A et al. Importance in diagnosis of gastritis of detection by PCR of the cagA gene in Helicobacter pylori strains isolated from children. $J$ Clin Microbiol 1995; 33: 3300-3303.

30. Goodman KJ, Correa P, Tengana Aux HJ et al. Helicobacter pylori infection in the Colombian Andes: a population-based study of transmission pathways. Am J Epidemiol 1996; 144: 290-299.

31. Replogle ML, Glaser SL, Hiatt RA, Parsonnet J. Biological sex as a risk factor for Helicobacter pylori infection in healthy young adults. Am J Epidemiol 1995; 142: 856-863.

32. Thomas JE, Gibson GR, Darboe MK, Dale A, Weaver LT. Isolation of Helicobacter pylori from human faeces. Lancet 1992; 340: 1194-1195.

33. Blecker U, Hauser B, Lanciers S, Keymolen K, Vandenplas Y. Symptomatology of Helicobacter pylori infection in children. Acta Paediatr 1996; 85: 1156-1158.

34. Chan KL, Tam PK, Saing H. Long-term follow-up of childhood duodenal ulcers. J Pediatr Surg 1997; 32: 1609-1611.

35. Gottrand F, Cullu F, Turck D et al. Normal gastric histology in Helicobacter pylori-infected children. J Pediatr Gastroenterol Nutr 1997; 25: 74-78.

36. Brenner H, Rothenbacher D, Bode G, Adler G. Parental history of gastric or duodenal ulcer and prevalence of Helicobacter pylori infection in preschool children: population based study. BMJ 1998; 316: 665 . 